\title{
Fatigue and fracture mechanical properties of selected concrete for subtle precast structural elements
}

\author{
Stanislav Seitl ${ }^{1,2 *}$, Petr Miarka ${ }^{1,2}$, and Vlastimil Bílek $^{3}$ \\ ${ }^{1}$ Institute of Physics of Materials, ASCR, v. v. i., Zizkova 22, 616 62, Brno, Czech Republic \\ ${ }^{2}$ Faculty of Civil Engineering, Brno University of Technology, Veveri 331/95, 60200 Brno, Czech \\ Republic \\ ${ }^{3}$ Faculty of Civil Engineering, VŠB Technical University of Ostrava, Ludvíka Podéště 1875/17, 708 \\ 33 Ostrava-Poruba Czech Republic
}

\begin{abstract}
Precast concrete elements used as a civil structure are usually made of a cement-based matrix and natural aggregates (such as sand, gravel, crushed stone, etc.). These structures are usually exposed not only to a static load but also to a cyclic load if they load the bearing part of a bridge (traffic etc.). The knowledge of fatigue and fracture mechanical characteristics is important in designing and modelling new structures. This paper introduces and compares fracture mechanical properties obtained from static and fatigue tests for three kinds of concrete. The focus was set on the bulk density, flexural and compressive cube strength, fracture toughness and fatigue properties ( $\mathrm{S}-\mathrm{N}-$ Wöhler curve). All of these tests are important for a practical application in the design of precast concrete structures. The experimental results were statistically analysed and they showed that the fatigue and mechanical fracture properties improved with improved mechanical parameters of concrete.
\end{abstract}

\section{Introduction}

Concrete made these days is not environmentally friendly because of the amount of cement used in mixture composition, which results in high $\mathrm{CO}_{2}$ production [1]. In order to reduce this $\mathrm{CO}_{2}$ production, new kinds of concrete have to be developed. Alkali-Activated Concrete (AAC) is designed with recycled materials in order to get a sustainable and ecologically friendly concrete mixture suitable for structural application [2].

The other concrete, called High Performance Concrete (HPC) with a compressive strength higher than $100 \mathrm{MPa}$, is designed to reduce material consumption per structural element and to improve structural behaviour. HPC can be used where weight reduction for the structure is important or where architectural design requires smaller and thinner structures for its esthetical value. Less use of concrete also means reduction of used materials, which eventually results in less $\mathrm{CO}_{2}$ consumed per structure.

\footnotetext{
*Corresponding author: seitl@ipm.cz, seitl.s@ @fce.vutbr.cz
} 
Both AAC and HPC should reduce the amount of Portland cement used in the mixture composition, which is the main reason why concrete produces a high amount of $\mathrm{CO}_{2}$ in its production.

The aim of long-term research is to design and prepare concrete mixtures suitable for precast elements, which will result in the total weight reduction of structure. Typically produced precast elements are light frames and beams for small span bridges. These subtle structural elements have to be designed with higher attention to durability, fatigue behaviour and fracture behaviour.

Both AAC and HPC are compared to concrete C50/60, which is commonly used in production of concrete precast and pre-fabricated structural elements (e.g. double T-shaped beam elements for roofing). However, this type of concrete is characterized by a high cement content, which increases production expenses and has a high impact on the environment. This is also the reason to compare it with the newer mixtures (AAC and HPC) so C50/60 can be partly or completely replaced in future structural production.

The investigated and compared properties were the bulk density, the flexural strength, compressive strength, the fracture toughness and the fatigue properties presented by the Wöhler curve were tested during the research programme.

\section{Materials and their static properties}

In what follows, a mixture is introduced, then the mixture composition per $1 \mathrm{~m} 3$ is compared and finally the obtained mechanical properties are presented.

\section{$2.1 \mathrm{C} 50 / 60$}

The C 50/60 concrete type [3] was chosen for the study because it is typically used for prestressed precast elements which are produced nowadays. The studied concrete contains 450 $\mathrm{kg}$ of CEM I $42.5 \mathrm{R}$, the water to cement ratio $\mathrm{c} / \mathrm{w}$ is 0.40 . A fine aggregate was natural sand $0 / 4 \mathrm{~mm}$ and crushed aggregates $4 / 8 \mathrm{~mm}$ and $8 / 16 \mathrm{~mm}$ from high quality granite were used as well as drinking water. The concrete was mixed in a volume of $1 \mathrm{~m} 3$ and immediately poured into moulds. A polycarboxylates-based superplasticizer was used to reach good workability [4]

\subsection{HPC}

High performance concrete was designed with the intent to produce subtle elements. The maximum size of the aggregate was chosen $8 \mathrm{~mm}$. The aggregates were composed of natural sand $0 / 4 \mathrm{~mm}$ and crushed high quality granite $4 / 8 \mathrm{~mm}$. Portland cement CEM I $42.5 \mathrm{R}$ was used with three mineral admixtures. The first was metakaolin with strong pozzolanic properties. The second and third admixtures were chosen to reach synergy in ternary binders [5] based on experiments, see for example [6]. Generally, a binder consists at $81 \%$ of CEM I $42.5 \mathrm{R}$, at $9.5 \%$ of metakaolin, at $7.5 \%$ of GBFS and at $2.5 \%$ of limestone. Water / binder ratio was 0.22 . A polycarboxylate based superplasticizer was selected based on its compatibility with cement. The concrete was mixed in volume $0.7 \mathrm{~m} 3$ and poured into moulds.

\subsection{AAC}

Alkali-activated concrete (AAC) was designed based on formerly performed tests $[6,7]$. The mixture composition is shown in [8]. The dry mass of the activator was $8 \%$ and the water to 
slag ratio was 0.45 . Sodium water glass and potassium hydroxide were combined to reduce efflorescence and an appropriate silicate modulus of the activator $(\mathrm{M}=0.67$ or mass ratio $\left(\mathrm{K}_{2} \mathrm{O}+\mathrm{Na}_{2} \mathrm{O}\right) / \mathrm{SiO}_{2}$ is $\left.60 / 40\right)$. This composition of the activator is convenient in terms of both setting and strengths. A naphthalene based plasticizer was also used for better workability of the mixture. All of the specimens were carefully enveloped with PE-foil (to prevent moisture exchange with the environment) and stored outside the laboratory (temperature $\approx 5 \div 25^{\circ} \mathrm{C}$ during 28 days).

The comparison of each material's admixture present in the mixture composition per $1 \mathrm{~m}$ 3 is presented in Table 1 .

Table 1. Composition of $1 \mathrm{~m}^{3}$ of concrete mixtures, [kg].

\begin{tabular}{|c|c|c|c|}
\hline & C50/60 & HPC & AAC \\
\hline CEM I 42.5 R & 450 & 650 & - \\
\hline ground granulated blast furnace slag & 0 & 60 & 450 \\
\hline limestone & 0 & 15 & 0 \\
\hline metakaoline & 0 & 75 & 0 \\
\hline superplasticizer (PCC) & 4.5 & 17 & 0 \\
\hline plasticizer (PNS) & 0 & 0 & 10 \\
\hline water & 180 & 165 & 159 \\
\hline natural sand 0/4 mm & 690 & 400 & 855 \\
\hline crushed aggregate 4/8 (granite) & 215 & 600 & 385 \\
\hline crushed aggregate 8/16 (granite) & 845 & 0 & 400 \\
\hline sodium water glass (silicate modulus Ms $=2.0)$ & 0 & 0 & 45 \\
\hline $50 \%$ solution of KOH & 0 & 0 & 34 \\
\hline
\end{tabular}

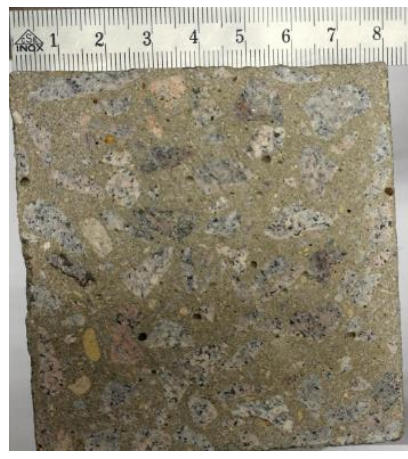

C50/60

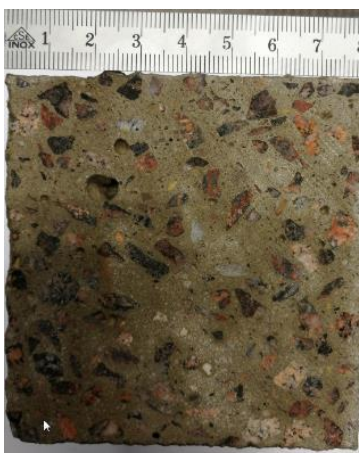

HPC

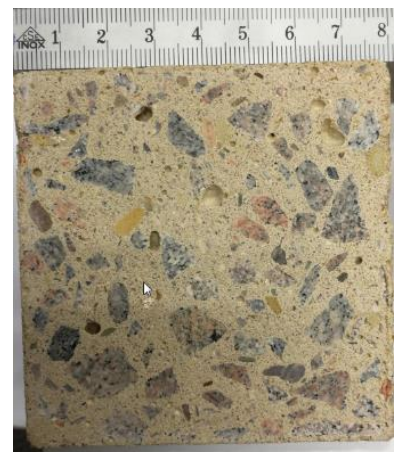

AAC

Fig. 1. Size, geometry and dispersion of aggregates in the studied concrete specimens. 


\subsection{Comparison of concrete investigated properties}

The standards used to test mechanical properties for description of material behaviour are mentioned in Table 2 (measured mechanical properties from the tests were the compressive cube and cylindrical strength at the age of 28 days, the static Young modulus of elasticity measured in cylinders $150 \mathrm{~mm} \times 300 \mathrm{~mm}$, the indirect tensile strength and the value of bulk density). To obtain mean values and standard deviation for each experiment, three or five samples per test were used. For verification of obtained mechanical properties the selected values were checked by well-known formulas, see for tensile strength according to EN19921-1[18] and for Young's modulus in accordance with Carrasquillo's et al. formula [9]:

$$
\begin{gathered}
f_{c t m}=2.12 \ln \left(1+\frac{f_{c}}{10}\right), \\
E=3320 f_{\mathrm{C}}^{1 / 2}+6900,
\end{gathered}
$$

where $f \mathrm{c}$ is compressive cube strength in $\mathrm{MPa}$.

Due to mixing concrete in the industrial mixer, the mechanical properties especially compressive strengths were lower compared to laboratory tests.

Table 2. Mechanical parameters with standard deviation of tested concrete at 28 days and comparison with selected values obtain from equation (1-2).

\begin{tabular}{|c|c|c|c|}
\hline & Material C50/60 & HPC & AAC \\
\hline $\begin{array}{c}\text { Compressive cube } \\
\text { strength } f_{\text {c_cube }[\mathrm{MPa}]}\end{array}$ & $85.8 \pm 2.9$ & $106.2 \pm 2.5$ & $62.0 \pm 1.5$ \\
\hline $\begin{array}{c}\text { Compressive cylindrical } \\
\text { strength } f_{\text {c_cyl }}[\mathrm{MPa}]\end{array}$ & $72.8 \pm 2.5$ & $94.1 \pm 3.1$ & $48.0 \pm 3.4$ \\
\hline $\begin{array}{c}\text { Young's Modulus } \\
E[\mathrm{GPa}]\end{array}$ & $38.3 \pm 0.3$ & $41.0 \pm 0.6$ & $26.3 \pm 1.1$ \\
\hline $\begin{array}{c}\text { Young's Modulus } \\
{[\text { GPa] }- \text { calculated }}\end{array}$ & 37.65 & 41.08 & 33.04 \\
\hline $\begin{array}{c}\text { Indirect tensile strength } \\
f_{\mathrm{t}}[\mathrm{MPa}]\end{array}$ & $5.515 \pm 0.31$ & $6.43 \pm 0.3$ & $3.15 \pm 0.3$ \\
\hline $\begin{array}{c}\text { Tensile strength under } \\
\text { concentric axial } \\
\text { loading } f_{\text {te }}[\mathrm{MPa}]- \\
\text { calculated }\end{array}$ & $2390 \pm 27.32$ & $2395.93 \pm 87.60$ & $2281 \pm 20.07$ \\
\hline $\begin{array}{c}\text { Bulk density } \\
\rho[\mathrm{kg} / \mathrm{m} 3]\end{array}$ & 4.79 & 5.19 & 4.18 \\
\hline
\end{tabular}




\section{Experimental data processing procedure}

Fatigue properties were measured on the three-point bend test (3PBT) geometry with a notch in the mid span of the specimen. The depth of the notches was $4 \mathrm{~mm}$ for fatigue tests. The fatigue tests were carried out by using an experimental set-up shown in Fig. 2 (right). The controlled values for temperature and relative humidity were equal to $23 \pm 2{ }^{\circ} \mathrm{C}$ and $50 \% \pm$ $2 \%$ respectively. The fatigue experiments were carried out using a computer-controlled servo-hydraulic testing machine under the load control. The stress ratio $R$ (defined as the quotient of minimum $P_{\min }$ and maximum $P_{\max }$ load of a sinusoidal wave in each cycle) was equal to 0.1 . The load frequency used for all tests was equal to $10 \mathrm{~Hz}$. The fatigue endurance limit was determined on the basis of an $S-N$ curve. The limit of $2 \times 10^{6}$ cycles to fracture was used to consider the applied stress amplitude as safe for loading during the whole component lifetime. The testing procedure based on applying cyclic loading with a defined stress amplitude to determine the number of cycles to the fracture was described by multiple researchers [10-17].

The formula for fitting the experimentally obtained data from the fatigue test used in this paper is based on empirically derived $S$ - $N$ diagrams known as Wöhler curves:

where:

$$
S=A N^{B},
$$

$A, B$ are the material constants characterising the $S-N$ curve.

The fatigue behaviour of a heterogeneous material like concrete is far from being ideal and the results are usually highly scattered; therefore, it is necessary to determine not only the analytical expression but also the index of dispersion.
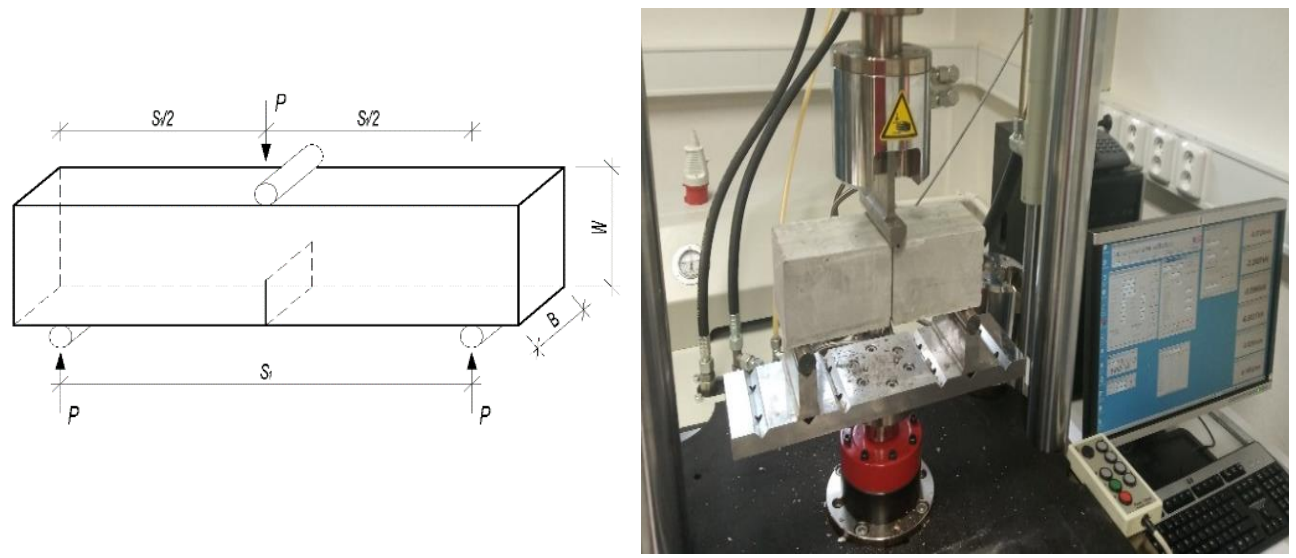

Fig. 2. Sketch of a used specimen for fatigue tests and experimental set-up.

\section{Results and discussion}

A comparison of the experimentally obtained fatigue results for HPC and C50/60 are shown in Fig. 3, where the bending stress amplitude [MPa] applied during the fatigue experiments is plotted against the logarithm of the number of cycles to failure or at $2 \times 10^{6}$ cycles [N], a limited number of cycles, for run-outs i.e. for unbroken specimens. The fatigue behaviour of HPC has higher values according to the ratio in the compressive strength of studied concrete mixtures. 


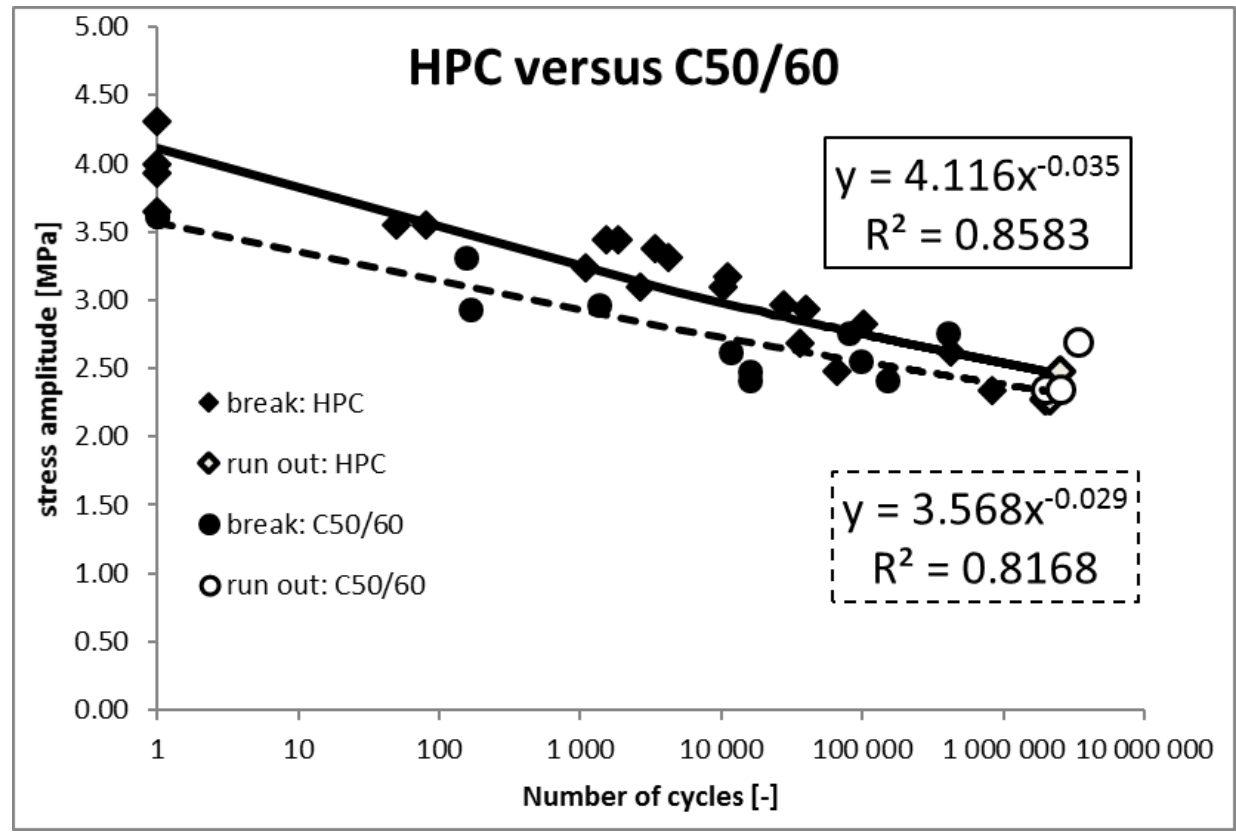

Fig. 3. $S$ - $N$ diagrams of the tested concrete mixture HPC and C50/60 (black symbol: broken specimen; white symbol: unbroken specimen).

A comparison of the experimentally obtained fatigue results for AAC and C50/60 are shown in Fig. 4, where the bending stress amplitude [MPa] applied during the fatigue experiments is plotted against the logarithm of the number of cycles to failure or at $2 \times 10^{6}$ cycles [N], a limited number of cycles, for run-outs i.e. for unbroken specimens [10].

The values of A, B described fatigue behaviour of C50/60, HPC and AAC with the index of dispersion are shown with the index of dispersion in Tab.3

Table 3. Values of constants $A, B$ described fatigue behaviour of C50/60, HPC and AAC with the index of dispersion.

\begin{tabular}{|c|c|c|c|}
\hline Concrete & C50/60 & HPC & AAC \\
\hline$A$ & 3.568 & 4.116 & 2.209 \\
\hline$B$ & -0.029 & -0.035 & -0.036 \\
\hline $\mathrm{R}^{2}$ & 0.8168 & 0.8583 & 0.8713 \\
\hline
\end{tabular}

The C50/60 material shows lower values of tensile strength than the HPC but, on the other hand, similar fatigue resistance, as shown in Fig. 5. The lowest value of fatigue resistance is for AAC material.

Comparison of fatigue resistance with data from literature $\mathrm{C} 45 / 55$ and $\mathrm{AAC}$ with average compressive strength $78 \mathrm{MPa}$, see in [13]. 


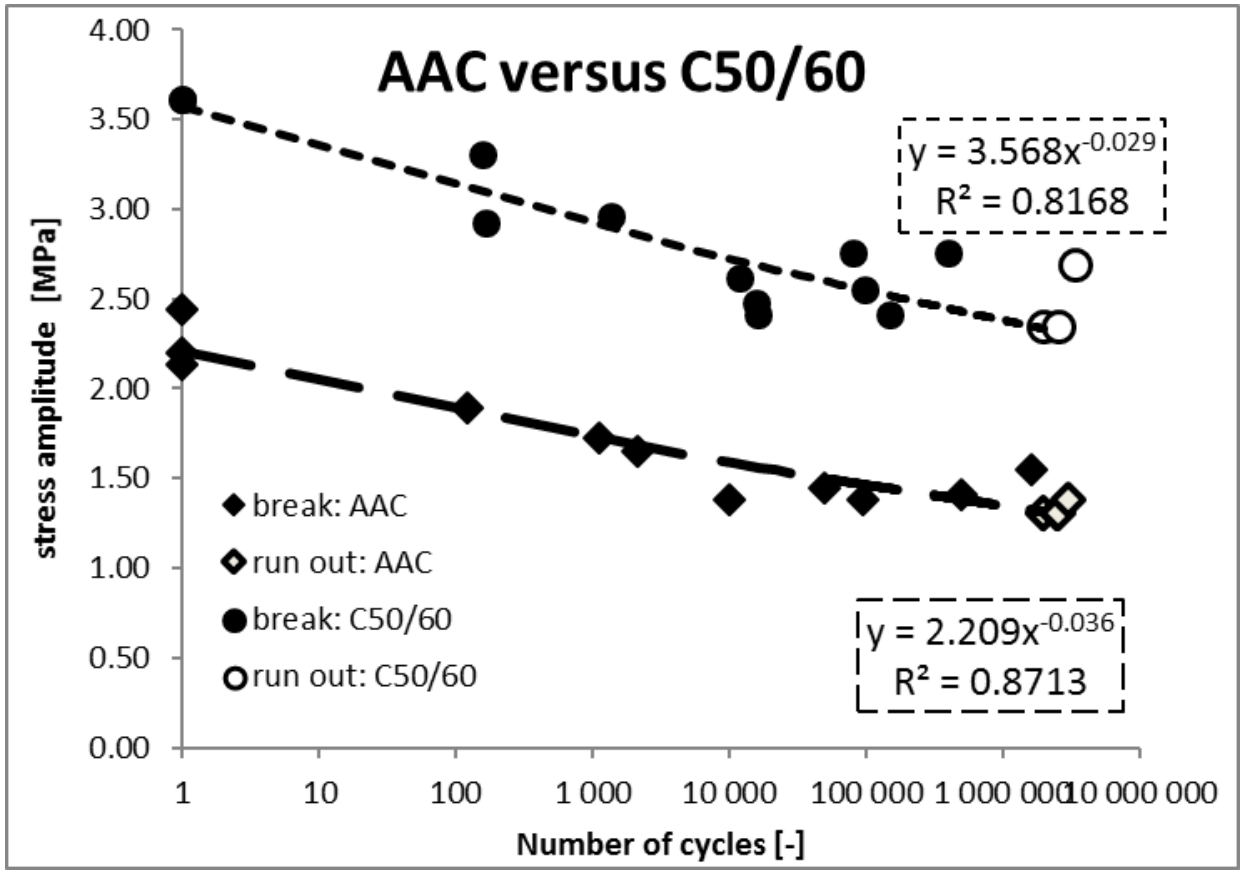

Fig. 4. $S$ - $N$ diagrams of the tested concrete mixture AAC and C50/60 (black symbol: broken specimen; white symbol: unbroken specimen).

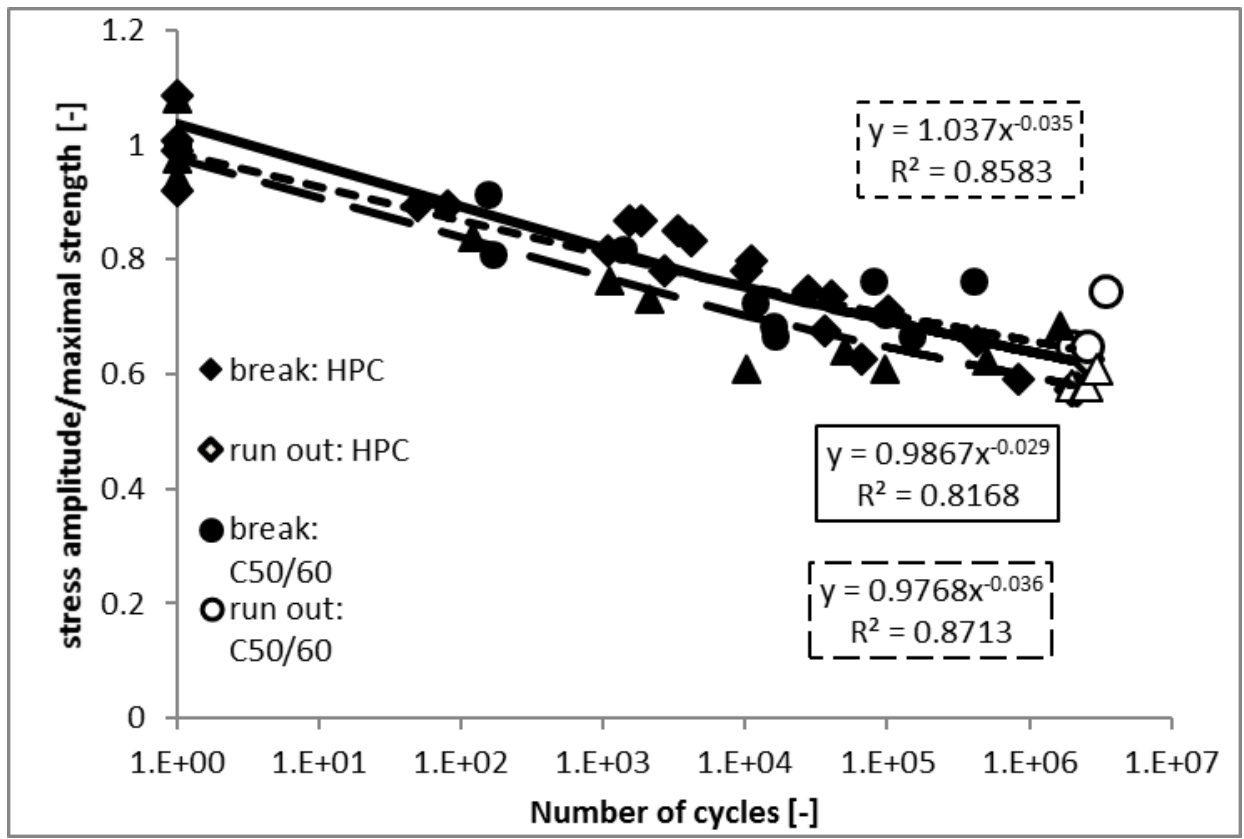

Fig. 5. Comparison of the $S$ - $N$ curves for AAC, HPC and C50/60 concrete fatigue resistance. The values are normalized by the static tensile strength. 


\section{Conclusions}

From the presented experimental research work following conclusions can be drawn:

- Three kinds of concrete were investigated, namely, the HPC, AAC and the C50/60 concrete, all of them being different based composites from a chemical point of view, used in civil engineering application.

- The HPC showed better performance to fatigue load in comparison with the C50/60, while the AAC showed lower resistance to fatigue load.

This paper presents results obtained within the project No. FAST-S-19-5896. The first author would like to acknowledge the support of the project No. 8J18AT009 (7AMB187AT) - Failure initiation and fracture of quasi-brittle building materials.

\section{References}

1. R. Aandrew, Global CO2 emissions from cement production. Earth System Science Data, 10.1: 195 (2018)

2. M. Abdulkareem, J. Havukainen, M. Horttanainen, Jour of Cleaner Production, 236, 117601 (2019)

3. T. Zimmermann, D. Lehky, Int Jour of Fract 192(2), (2015)

4. S. Seitl, P. Miarka, V. Bílek, Theor. appl. fract. mec., 97, 108-119 (2018)

5. S. Adu-Amankwah; M. Zajac, C. Stabler, B. Lothenbach. Cem. Con. Res. 100, 96-109 (2017)

6. V. Bilek, D. Pytlik, M. Bambuchova, Key Engeneering Materials, 761, 120-123 (2018)

7. V. Bílek, T. Opravil, F. Soukal, In: First International Conference on Advances in Chemically-Activated Materials. RILEM Publications SARL, 28-35 (2010)

8. P. Miarka, S. Seitl, O. Sucharda, V. Bílek, Proc Struc Int. 17, 610-617 (2019)

9. R. L. Carrasquillo, A. H. Nilson, F. O. Slate, Journal of the American Concrete Institute, 78(3), 171-178, (1981)

10. M. K. Lee, B. I. G. Barr, Cem Conc Com, 26(4), 299-305, (2004)

11. S. Korte, V. Boel, W. De Corte, G. De Schutter. Key Engineering Materials, 627, $333-$ 336, (2015).

12. S. Korte, V. Boel, W. De Corte, G. De Schutter. Str. Conc., 15(4) 575-589 (2014)

13. S. Seitl, V. Bílek, Z. Keršner, International Journal of Research in Engineering and Technology, 03(13) | ICNTCC-2014 203-208 (2014)

14. S. Seitl, P. Miarka, J. Klusák, J., Domski, J. Katzer, H. Šimonová, Z. Keršner, Key Engineering Materials 761, 111-115, (2018)

15. S. Seitl, H. Šimonová, Z. Keršner, A. Fernández-Canteli, Applied Mechanics and Materials 121-126, 2726-2729, (2012)

16. H. Šimonová, B. Kucharczyková, I. Havlíková, S. Seitl, Z. Keršner, Key Engineering Materials 592-593, 801-804, (2014)

17. S. Seitl, P. Miarka, H. Šimonová, P. Frantík, Z. Keršner, J. Domski, J. Katzer, Periodica Polytechnica Civil Engineering, 63(1), 152-159, (2019)

18. EN 1992-1-1 (English): Eurocode 2: Design of concrete structures - Part 1-1: General rules and rules for buildings (2004) 